\title{
The analysis of digitalization impact on personnel functions in logistics
}

\author{
Aleksandr Bavrin ${ }^{1}$,Violetta Koop ${ }^{1}$, Nikita Lukashevich ${ }^{1}$, Zoya Simakova ${ }^{1}$, and Egor \\ Temirgaliev ${ }^{1, *}$ \\ ${ }^{1}$ Peter the Great Saint Petersburg Polytechnic University, 29, Polytechnicheskaya str., 195251, St. \\ Petersburg, Russia
}

\begin{abstract}
The article discusses the main types of employment in logistics. The functionality of positions in purchasing, warehousing, transport and information logistics, as well as in external economic activities, is analyzed in sufficient detail. The following positions are considered: purchasing agent, railway transport service agent, car driver, dispatcher, vehicle maintenance engineer, transport organization and management engineer, logist, logistician, foreign economic activity Manager, air transportation Manager, purchasing Manager, logistics Manager, customs Manager, warehouse Manager, operational logistician, vehicle auditor, marine transportation specialist, customs broker, transport planner, freighter, freight forwarder, freight forwarding agent, specialist in the field of digital logistics, specialist of the Contract service. Digitalization is capable of influencing the job responsibilities of logistics personnel in the fact that over time the need for human personnel decreases. In this regard, there is a need to be able to identify such functions that can be replaced by information or automated systems. The main aspects of the impact of digitalization on logistics are indicated: transport logistics, purchasing logistics, information logistics, customs logistics.
\end{abstract}

\section{Introduction}

In this paper, the authors propose to pay attention to the impact of digitalization in logistics on the job responsibilities of personnel. Currently, in many sources you can find information about the strong impact of digitalization on logistics. You can often come across a statement about reducing the need for human personnel. It is indicated that thanks to digitalization, the introduction of information systems, and automation, a wide range of human operations will become unclaimed. In this article, the authors propose to consider in detail the job responsibilities of people working in logistics, and the possibility of replacing some functions with information or automated systems.

\footnotetext{
* Corresponding author: temirgaliev@kafedrapik.ru
} 


\section{Materials and Methods}

\subsection{Purchasing agent}

A purchasing agent (procurement /supply agent) conducts market analysis to find suppliers, draws up supply contracts, controls transportation and timely receipt of goods.

A purchasing agent performs the following activities (functions):

- Draws up documentation for received and dispatched goods, orders containers, other containers, as well as vehicles for their delivery.

- Makes unplanned purchases of materials.

- Sends inventory items to the address of the company or accompanies goods on the way, ensures safety and promotes their timely delivery.

- Checks the condition of the cargo, takes measures to replace material values in case of external defects.

- Determines the mode of transportation of perishable and dangerous goods, monitors the compliance of containers with transported goods, placement of goods during transportation, monitors compliance with safety requirements during loading and unloading operations.

- Takes measures to improve the efficiency of the use of material resources by reducing the costs related to their acquisition, delivery and storage [1].

\subsection{Railway transport services agent}

The agent of transport services for railway transport is engaged in the implementation of a range of transport services for shippers and consignees of railway transport. The main goal of his activities is to ensure the sustainable functioning of railways in the transport services market.

His responsibilities include:

- Informing clients about the rules and conditions of goods carriage.

- Acceptance of applications for cargo transportation.

- Execution and verification of shipping documents for the acceptance of cargo for transportation, issuance of railway consignment notes to consignees.

- Acceptance and initial consideration of claims on issues arising from the provision of services related to the carriage of goods

- Collecting primary marketing information about shipping

- Registration of statements, acts of the general form, documents for the collection of fines

- Registration of reports and books of established forms [2].

\subsection{Car driver}

The driver drives a passenger car, bus or truck vehicle, ensures the correct operation of the car, withstands the break-in mode of a new car, takes care of the timely oil change, tightens loose threaded connections, systematically checks the oil pressure in the engine lubrication system and the fuel in the tank, the coolant temperature ...

\subsection{Dispatcher}

A dispatcher is a specialist in monitoring the current situation, developing operational decisions and organizing the work of performers. A dispatcher is one of those professions, a representative of which can realize himself in absolutely different areas. Dispatchers are 
needed to control the movement of taxis, trains, planes, when working with complex mechanisms. For specialists not to be distracted from performing their functions, dispatchers come to them for help. They are the ones who make up the program of all the cases that await the employees of any firm or organization. Depending on the field of activity in which the dispatchers work, they either answer customers calls, or develop a convenient operating mode for the organization, or monitor the procurement of materials necessary for the enterprise, or draw up a movement pattern for ground or air transport. How will the nature of dispatcher work change in the future? The transport infrastructure is becoming more complex, cargo delivery is becoming modular, freight and passenger flows are increasing, and users' requirements for quality and delivery speed are increasing. It is more and more difficult for a person to cope with such tasks. However, automated control and tracking systems for shipments with all kinds of sensors and the possibility of satellite monitoring, intelligent programs for the development of delivery routes and their tracking are already beginning to be introduced en masse. A person is needed only for control at the highest level - making decisions in the event of emergency, difficult situations. Therefore, in the profession of forwarders, dispatchers and logisticians, the number of workers will gradually decrease, and the intensity and complexity of their work will increase [1].

\subsection{Engineer for the maintenance of vehicles}

Vehicle maintenance engineer calculates vehicle interaction schemes; examines freight and passenger flows, road conditions and traffic patterns in order to optimize transportation; works at motor transport companies, scientific and design organizations.

His functions are:

- Organization of the work of drivers;

- Development of uniform standards, rules for the maintenance and repairing of the organization's vehicles;

- Organization of work for improving the maintenance and repair of vehicles;

- Participation in the process of selecting a service provider and concluding contracts for the maintenance and repair of vehicles;

- Participation in the formation and adherence to the budget for the repair and maintenance of transport;

- Control over the technical condition of transport;

- Optimization of repair costs [2].

\subsection{Engineer for the organization of transportation and transport management}

The engineer for the organization of transportation and transport management is engaged in the preparation of rational transportation routes, works with passenger flows and in the forwarding field. For work, you need: specialized education, knowledge in the field of organization of transportation, management of transport services.

The specialist must have a mathematical mindset, have attentiveness, analytical skills, responsibility and logic. An engineer in this area develops routes, works to improve the efficiency of using vehicles, draws up schemes for the operation of vehicles and unloading equipment, analyzes the nature of freight and passenger flows.

In addition, a specialist can perform management functions at transport enterprises, carry out marketing of transport activities, engage in logistics, etc. He can work in transport departments and transport companies, design organizations and research institutes. The type of professional environment by Holland: 
If the Engineer for the organization of transportation and transport management is engaged in drawing up rational transportation routes, works with passenger flows, then his activity belongs to the office (conventional) type of professional environment.

If a specialist is engaged in management, management in logistics, assumes responsibility for the result, then his activity belongs to the entrepreneurial (entrepreneurial) type of professional environment.

Type of profession by object of labor in the classification of professions by Klimov:

The profession of an Engineer for the organization of transportation and transport management in most cases, according to the object of labor, can be attributed to the type of person-symbol system [3].

\subsection{Logist}

A logistics specialist is a specialist who ensures the efficient physical movement of various goods and their storage. For the cargo to reach its destination on time, safely and in the right condition, it is necessary to plan its physical movement by a variety of vehicles, placement in temporary storage warehouses, and overloading. The final cost of the product in the distribution network depends on the efficiency of the logistician, since the share of logistics costs can be more than half of the cost of the goods. The logistician finds solutions that are optimal in terms of price and time.

The main task of the logistician is to ensure the delivery of goods from point A to point $\mathrm{B}$, minimizing costs to the maximum. Optimize operations related to the storage and transportation of goods, saving money where possible in principle. The logistician is in contact with the purchasing and sales departments, with the specialists responsible for packing, storing and transporting goods, working with the customs authorities, etc.

How will the nature of work and the demand for the profession of "Logist" change in the future?

The transport infrastructure is becoming more complex, cargo delivery is becoming modular, freight and passenger flows are increasing, and users requirements for quality and delivery speed are increasing. It is more and more difficult for a person to cope with such tasks. However, automated control and tracking systems for shipments with all kinds of sensors and the possibility of satellite monitoring, intelligent programs for the development of delivery routes and their tracking are already beginning to be introduced en masse. A person is needed only for control at the highest level - making decisions in the event of emergency, difficult situations. Therefore, in the profession of dispatchers and logisticians, the number of workers will gradually decrease, and the intensity and complexity of their work will increase [4].

\subsection{Logistician}

Tracks transportation (auto, air, sea), plans purchases, controls warehouses, performs customs preparation, prepares customs documentation, negotiates with transport companies and prepares contracts.

How will the nature of work and the demand for the profession of "Logistician" change in the future?

The transport infrastructure is becoming more complex, cargo delivery is becoming modular, freight and passenger flows are increasing, and user requirements for quality and delivery speed are increasing. It is more and more difficult for a person to cope with such tasks. However, automated control and tracking systems for shipments with all kinds of sensors and the possibility of satellite monitoring, intelligent programs for the development of delivery routes and their tracking are already beginning to be introduced en masse. A 
person is needed only for control at the highest level - making decisions in the event of emergency, difficult situations. Therefore, in the profession of dispatchers and logisticians, the number of workers will gradually decrease, and the intensity and complexity of their work will increase [3].

\subsection{Foreign trade Manager}

The position of a foreign economic activity manager at different enterprises can sound differently: procurement manager, export and import manager, logistician, purchaser, customs declarant. Whatever the name of this specialist, it is he who ensures the promotion of goods from seller to buyer, if they are located in different countries, i.e. supervises all operations related to the foreign economic activity of the company. Professionals in the field of foreign economic activity are highly valued in the labor market. There are two main specializations for this profession. In the importing company, the foreign economic activity manager performs the functions of a purchaser, and in the field of export he has more responsibilities as a seller. Foreign trade managers are needed in trading and manufacturing companies that sell or buy something abroad.

The duties of the foreign economic activity manager are to organize the movement of goods across the border inland or out of the country (briefly):

- conclusion and support of foreign trade contracts;

- negotiating and business correspondence with logistics companies and brokers on terms of work and optimization of supplies;

- control and support of supplies at all stages - from placement to receipt of an order;

- control of timely payment of export and import payments;

- preparation of the necessary accompanying documentation (delivery schedules, certificates, permits, licenses).

Also, the duties of a foreign economic activity manager may include:

- participation in international exhibitions;

- search for new products and suppliers abroad. detail):

The Foreign Economic Activity Manager performs the following job duties (in more

- Manages the development of proposals and measures for the development of progressive forms of foreign economic relations, scientific, technical and economic cooperation with foreign countries.

- Establishes direct production and scientific and technical ties, solves issues of production and technical cooperation with enterprises and firms of other countries.

- Develops a feasibility study for the establishment of direct production ties, the creation of joint ventures.

- Carries out preparation and participates in negotiations with foreign companies.

- Organizes, in accordance with the established procedure, the reception of representatives of foreign and domestic enterprises (firms) who have arrived to resolve issues on foreign economic activity.

- Develops recommendations for the development of new forms of foreign economic cooperation.

- Organizes collection, systematization, study and generalization of information materials on marketing; on the economic, sales and other activities of enterprises (firms) with which cooperation agreements have been concluded; preparation of abstracts and annotations, thematic reviews on the competitiveness of the products manufactured by the enterprise and the requirements for similar products in the world market. 
- Organizes work to increase the volume of export deliveries, involve other types of goods and resources in the export.

- Supervises the implementation of contracts with foreign trade organizations for the supply of products for export and the supply of imported products by foreign firms.

- Carries out coordination of the work of the enterprise in the field of foreign economic activity with the relevant republican departments.

- Prepares information for the management of the enterprise on all issues of foreign economic relations.

- Manages subordinate employees [4].

\subsection{Air Freight Manager}

The profession of an air transportation manager often combines the functions of a sales manager, customer service and a professional logistician. The duties of a sales manager for air transportation include negotiations and coordination with the client the conditions for transporting his cargo, booking air transportation, calculating tariffs and preparing related documentation. The air transportation sales manager works with the client at all stages of the provision of services, controls the entire process of cargo transportation and the fulfillment of the stated obligations.

\subsection{Purchasing manager}

A purchasing manager is a specialist who purchases consumables, equipment, tools, etc. necessary for the company. The cost of the final product and its quality depend on his effective work, the ability to find the optimal product in terms of price-quality ratio. He is engaged in the supply of a company or enterprise: he studies the market, builds a strategy, negotiates with suppliers, assists in solving issues related to transportation and documentation (registry, customs, etc.). In many ways, the profession of a purchasing manager is similar to a logistician.

Briefly: supplying the enterprise with raw materials, analyzing customer preferences, finding suppliers and tracking delivery times.

Labor responsibilities:

The purchasing manager controls the filling of the warehouse with goods. Plans warehouse stocks. Selects suppliers according to the criterion of the best prices and conditions. Places an order and monitors the receipt of payments. Tracks the terms of shipment of goods and the movement of goods. Monitors the quality of products and considers issues with claims to suppliers [5].

\subsection{Logistics manager}

A logistics manager is a line manager responsible for delivering goods on time, from finding and contracting shipping service providers, interacting with customs authorities to efficiently storing goods. His mission is to provide a delivery infrastructure at the lowest cost.

Unlike the profession of a logistician, the profession of a logistics manager is multifaceted: he specializes in planning and analytics, monitors transportation, the availability of certain goods in the warehouse, and their quality. However, the main task of a logistics manager is transportation, which provides for the most favorable conditions and, which is important, low cost, minimum costs. A capable logistician can reduce company costs by an average of $15-30 \%$. The level of workload and complexity of the logistician's work depends on the scale of the company with which he cooperates. 
How will the nature of work and the demand for the profession of "Logistics manager" change in the future?

The transport infrastructure is becoming more complex, cargo delivery is becoming modular, freight and passenger flows are increasing, and user requirements for quality and delivery speed are increasing. It is more and more difficult for a person to cope with such tasks. However, automated control and tracking systems for shipments with all kinds of sensors and the possibility of satellite monitoring, intelligent programs for the development of delivery routes and their tracking are already beginning to be introduced en masse. A person is needed only for control at the highest level - making decisions in the event of emergency, difficult situations. Therefore, in the profession of dispatchers and logisticians, the number of workers will gradually decrease, and the intensity and complexity of their work will increase [5].

\subsection{Manager for work with customs}

Works in customs terminals, at the border, is engaged in the export or import of goods; prepares customs declarations and other documents for export, import and transit of goods; controls dispatch, passage through customs control and receipt of cargo.

\subsection{Warehouse manager (storekeeper, warehouse technician)}

A storekeeper or warehouse manager is a specialist who is responsible for organizing the work of the warehouse: storage, transportation within the warehouse, reloading, sorting of goods, accounting of goods (acceptance, delivery, coding), efficient distribution of storage objects in the warehouse, operation of automated warehouse equipment, the work of warehouse personnel.

The field of activity of a storekeeper or warehouse manager is very responsible and complex. Warehouse activities use sophisticated equipment, specialized computer programs, and only a highly qualified specialist can cope with all this.

As in most divisions of any company, a clear line of management has been built in warehouse activity, starting from a simple storekeeper to a warehouse manager.

Any manager-storekeeper must be well versed in the warehouse documentation, own special computer programs that facilitate its work and use various office equipment required for work without problems. Also, the storekeeper must clearly understand the internal location of the warehouse, know what and where to put, how much and to whom to give.

The warehouse manager must be able to work competently with personnel and goods. He must clearly follow the storage instructions and organize the smooth operation of the warehouse terminal, even if this requires translation of documents into Russian. Here, it is important to clearly distribute responsibilities between warehouse workers, so that everyone knows what he should do and who specifically obey.

A warehouse is a clearly structured area, with or without shelving, where various items (so-called storage units) are stored.

The features of each warehouse depend on what kind of goods are in it.

For example, the warehouse of a grocery store is made up of rows of shelving and refrigeration units. Each rack has its own exact purpose: it is clear that a good storekeeper cannot store sausage with bread, and sweets cannot be stored with cheese.

In the factory warehouse, parts or tools necessary for the production of products are laid out on different racks. A special warehouse is intended for storage of finished products.

Everything that is stored in the warehouse - it does not matter whether it is products or spare parts - is called material values. And the storekeeper is a financially responsible person, as he is responsible for accepting values, placing them in a warehouse, storing, issuing and 
accounting. Not a single thing should be lost. Even if something is broken, the loss is scrupulously recorded.

In large warehouses, the storekeeper may be responsible for certain items and sections.

He can also do the picking of goods to order. Such a position (storekeeper-picker) is found in warehouses at organizations selling wholesale or retail by prior order.

The highest position in the warehouse economy is the warehouse manager (warehouse manager).

Ordinary storekeepers, warehouse workers (loaders, truck drivers, etc.) may be subordinate to him.

An ordinary storekeeper himself accepts the goods, assesses the integrity of the packaging, in some cases weighs, conducts an inventory, and maintains accounting documentation.

Issuing goods from the warehouse, he picks them up from the storage location, again assesses its integrity and enters a note in the accounting log that the goods have been issued. The storekeeper moves bulky or heavy goods using special trolleys. Ideally, this should be done by loaders, truck drivers, etc., but in small warehouses, the storekeeper does this himself. With such work, safety precautions must be strictly observed, otherwise injuries are inevitable.

The disadvantages of the profession include eternal drafts, without which not a single intensively operating warehouse can do: constant acceptance and delivery of goods means constantly open doors. (In modern warehouses, this problem is solved with the help of a competent layout of the premises.)

And finally, the third important issue: stored items can be dangerous in themselves. These are poisonous chemicals, fire hazardous and explosive substances. Storage requires special conditions and special safety precautions for handling [5].

\subsection{Operational logistician}

An operational logistician is a specialist who solves issues related to the optimization of various work processes (supply, storage, distribution, transportation, etc.), is engaged in planning, organizing, executing and controlling the movement and placement of material and non-material flows and resources.

The main activities of an operational logistician:

- $\quad$ Planning and organization of the logistics process in organizations.

- Management of logistics processes in procurement, production and distribution.

- Optimization of the organization's resources related to the management of material and non-material flows.

- $\quad$ Evaluation of the efficiency of logistics systems and control of logistics operations.

How will the nature of work and the demand for the "Operational Logistics" profession change in the future?

The transport infrastructure is becoming more complex, cargo delivery is becoming modular, freight and passenger flows are increasing, and user requirements for quality and delivery speed are increasing. It is more and more difficult for a person to cope with such tasks. However, automated control and tracking systems for shipments with all kinds of sensors and the possibility of satellite monitoring, intelligent programs for the development of delivery routes and their tracking are already beginning to be introduced en masse. A person is needed only for control at the highest level - making decisions in the event of emergency, difficult situations. Therefore, in the profession of dispatchers and logisticians, the number of workers will gradually decrease, and the intensity and complexity of their work will increase [6]. 


\subsection{Inspector of vehicles}

Controls the observance of transport release schedules on the line at trucking enterprises; monitors the correctness of tariffs, filling out documents for accounting for the work of transport; participates in audits of production and economic and financial activities.

\subsection{Specialist in shipping}

A sea freight specialist deals with processes related to the organization and management of sea freight:

- $\quad$ preparation and support of freight contracts,

- organization and coordination of cargo transportation,

- supply of ships,

- $\quad$ organization of bunkering,

- $\quad$ agency service and operation of ships, work with crews,

- $\quad$ work with suppliers, service agents for ships and crew members, work with repair organizations,

- $\quad$ support of transactions for the sale and purchase of ships, registration of ships, reflagging,

- work with various insurance companies in terms of ship insurance and ship owner's liability, as well as collection and preparation of documents for obtaining insurance compensation [7].

\subsection{Customs broker}

Carries out intermediary activities between clients and customs officials, prepares customs documents for the passage of goods across the border, fills out a customs declaration, calculates customs payments (excise taxes, duties, etc.). The cargo declarator must know the rules for processing customs declarations, commodity codes, bank documents, exchange rates, invoice and customs value of goods, types and classification of enterprises, principles of execution and conclusion of contracts and agreements, delivery conditions.

\subsection{Transport planner}

The duties of the transport planner include planning the development of the transport infrastructure of cities, agglomerations, intercity connections, both for passenger traffic and freight; development of strategies, concepts, programs and plans for the development of transport infrastructure; planning and conducting surveys of drivers and passengers, measurements of transport and passenger flows, including with the involvement of interviewers; analysis and processing of data on transport and passenger flows.

\subsection{Freighter}

The charterer is a specialist of average qualification in the field of transport services. The main responsibilities of the charterer include providing a vehicle for transporting people, baggage (luggage) or cargo.

His responsibilities include:

- $\quad$ chartering (hiring) of ships;

- $\quad$ negotiations with ship-owners;

- $\quad$ organization of the conclusion of contracts on behalf of ship-owners; 
- clarifying the terms of the contract and ensuring compliance with them.

A charterer is a carrier, so all responsibility for moving vehicles rests on him. This applies to losses, various types of damage and delays.

\subsection{Freight forwarder}

A freight forwarder is a specialist in the transport of goods. He accompanies the goods, is responsible for the cargo during its transportation, and monitors the safety.

An internal freight forwarder is engaged in the delivery of goods to customers. His task is to receive the goods from the storekeeper according to the documents and promptly deliver it to retail outlets within the city or region.

The tasks of an international forwarder are much broader. He must independently:

- $\quad$ choose a method of transportation and develop a route of movement;

- $\quad$ charter a vehicle (ship, plane, railway carriages, car);

- receive the goods from the shipper and a package of accompanying documents;

- control the loading, sealing of the vehicle;

- $\quad$ carry out customs clearance, cargo insurance;

- accompany the cargo, controlling the conditions of transportation;

- deliver and transfer the goods to the consignee strictly within the agreed time frame;

- $\quad$ ensure that both parties receive the correct documents.

How will the nature of work and the relevance of the "Forwarder" profession change in the future?

The transport infrastructure is becoming more complex, cargo delivery is becoming modular, freight and passenger flows are increasing, and user requirements for quality and delivery speed are increasing. It is more and more difficult for a person to cope with such tasks. However, automated control and tracking systems for shipments with all kinds of sensors and the possibility of satellite monitoring, intelligent programs for the development of delivery routes and their tracking are already beginning to be introduced en masse. A person is needed only for control at the highest level - making decisions in the event of emergency, difficult situations. Therefore, in the profession of forwarders, dispatchers and logisticians, the number of workers will gradually decrease, and the intensity and complexity of their work will increase [7].

\subsection{Freight forwarding agent}

Accepts goods from warehouses in accordance with the accompanying documents; checks the integrity of the packaging, the sanitary condition of vehicles; monitors the implementation of loading and unloading operations, placement and storage of goods; accompanies goods to their destination, prepares acceptance documents.

How will the nature of work and the relevance of the profession of "Freight Forwarder" change in the future?

The transport infrastructure is becoming more complex, cargo delivery is becoming modular, freight and passenger flows are increasing, and user requirements for quality and delivery speed are increasing. It is more and more difficult for a person to cope with such tasks. However, automated control and tracking systems for shipments with all kinds of sensors and the possibility of satellite monitoring, intelligent programs for the development of delivery routes and their tracking are already beginning to be introduced en masse. A person is needed only for control at the highest level - making decisions in the event of emergency, difficult situations. Therefore, in the profession of forwarders, dispatchers and 
logisticians, the number of workers will gradually decrease, and the intensity and complexity of their work will increase.

\section{Results}

\subsection{Specialist in the field of digital logistics (Logistics analyst)}

The work of logistics systems specialists is related to the digital transformation of business processes, the formation of digital business models of logistics activities and supply chain management. The market is in demand for specialists with the skills and abilities to apply modern research methods and management technologies. Organizations are interested in logisticians who are able to optimize material and related flows in the context of the use of digital technologies in logistics systems. Specialists in this area must perform the following functionality: analytics, modeling and optimization of business processes in the logistics of production, supply, distribution, inventory management, warehouse, transport; Big Data analysis for decision making in the field of logistics systems; participate in projects of information integration in supply chains and implementation of electronic document management during transportation and customs procedures $[8,9,10]$.

\subsection{Employee / specialist of the Contract Service}

For government and budget organizations, purchasing agents and managers are more often referred to as contract service specialists. In connection with the need to carry out purchases in accordance with the legislation, specialists of the contract service must possess additional skills and abilities in legal regulation, the formation of tenders, determination of the minimum contract price, etc.

Compared to the specialists of commercial organizations, where unprofessional purchasing often leads to additional costs, mistakes of the specialists of the contract service can lead to fines and significant delays in deliveries.

From the point of view of procurement logistics, in the further decade, most of the routine operations for the purchase of goods and materials will be carried out using information remote technologies. First of all, these should include:

- search and selection of suppliers. The globalization of the market and the active development of information technology leads to the creation of a large number of online databases. Many of them have already evaluated suppliers and assigned ratings, which makes it easier for the buyer. The active development of technologies and the possibility of copying them leads to a decrease in price competition, so the importance of price selection of suppliers is reduced.

- verification of inventory items by time of receipt and quantity. Some organizations are already using RFID tags to simplify tracking the location of goods, speed up the receipt of goods and sorting in distribution centers. Thus, the active use of this technology will allow organizing the receipt of goods without the personal presence of an agent / purchasing manager. Accordingly, the manager only has to check the fulfillment of the delivery plan in the information system $[11,12]$.

- calculation of the quantity of goods for purchase and delivery times. Building up the big data base and improving artificial intelligence will make it possible to forecast needs and total costs better and take into account possible risks. Information systems, having independently calculated the need, will be able to place an order by analyzing suppliers in online resources. 
This profession will remain relevant in the future for enterprises producing high-tech products to order. In this case, the main functions of the purchasing manager will be the selection of suitable materials, as well as components manufactured to order. In this case, the manager will need additional engineering competencies or the procurement function will be carried out by specialists from production departments.

The above changes will be possible if enterprises continue to invest in informatization and enterprise automation. Today, even in developed countries, the level of industrial automation rarely exceeds $20 \%$, and in Russia only $10-15 \%$ of large enterprises use or plan to use industrial automation technologies in the near future. In addition to automation, it is necessary that all aspects of the enterprise have a single ERP system for fast data exchange. Implementation or transition to a unified information system will require reengineering of some of the business processes. However, for many medium and small businesses, the implementation of ERP systems will be too financially costly.

Conclusions: in the future, this profession will be significantly transformed, but, in view of the significant financial costs in the implementation of information technologies and production automation, in the nearest future, especially for Russia, no significant changes are expected $[13,14]$.

\subsection{Foreign trade Manager}

When considering the functional responsibilities of a foreign trade Manager, you can note the similarity with the purchasing/sales Manager, with a certain specificity - the need to ensure the movement of goods across the border [15].

Therefore, the possibility of automating his functions should be considered within the framework of processes occurring on the one hand - from the point of view of automating operations related to customs clearance, on the other hand-from the point of view of automating operations related to the international movement of goods.

Automation of issues related to customs clearance of goods and vehicles has been carried out for a long time. Today, various training programs for professions related to the implementation of foreign economic activity necessarily include skills in working with automated information systems. The development strategy of the customs service up to 2030 also provides for the large-scale use of innovative methods and digital technologies. As of the beginning of the current year, there were 12 electronic Declaration centers (e-Declaration centers), in 2020, their number will grow to 16 . According to the results, in $201967.9 \%$ of all declarations were processed in the CED (in accordance with the Comprehensive development program of the Federal customs service of Russia in 2019, the value of this indicator was planned at $60 \%$, so automation is ahead of schedule).

It seems logical to consider the Automation of international cargo movement on the example of sea transportation (as it is known, they provide about $75 \%$ of transportation between countries) [16-17].

One of the most significant events in the digitalization of international cargo movements is the creation in 2019 by A. P. Moller-Maersk, Hapag-Lloyd, Mediterranean Shipping Company (MSC) and Ocean Network Express (ONE) - world leaders in container transportation - of the Digital Container Shipping Association (Digital Container Shipping Association) in order to develop common IT standards and technical solutions for the entire Maritime industry. The Association plans to issue 5-7 resolutions a year. CMA CGM and MSC also announced their decision to join TradeLens. This is a blockchain platform for electronic document management in the field of cargo transportation, jointly developed by Maersk and IBM. Together with CMA CGM, MSC, Maerks and other ship owners registered on the platform. 
TradeLens will process data on almost half of the world's container cargo volume. Full digitalization of sea container transport is possible in the very near future. Even the COVID19 pandemic did not have a serious impact on sea cargo transportation - global demand for container transportation in August 2020 (despite a drop in the first half of the year) was estimated at 14.76 million TEU, which is $1.5 \%$ more than a year earlier.

Information technologies have also been introduced in major ports for quite a long time (unmanned container handling machines were first used in Rotterdam back in 1993). Today, the ports of Qingdao and Long-Beach operate fully automated terminals [18-19].

In Russia, attempts are still being made to introduce automated control systems and interaction of foreign trade participants (for example, the KPS "Sea port portal"), as for integrated automation, we can state a lag behind advanced information technologies.

Conclusion: the introduction of information technologies in the field of foreign trade managers' activity began in the 90s, and continues successfully today. However, in the coming years, we can talk only about automating routine operations (such as filling out and submitting documents). The use of blockchain platforms or full automation of technological processes in the processing of international cargo in the nearest future in Russia is not possible.

\subsection{Transport logistics}

In transport logistics, it makes sense to pay attention to the following changes that occur due to the use of modern information technologies and digitalization:

- Electronic document management eliminates the cost of printing documents and their delivery [20-21].

- The use of digital platforms to support all processes in the transport and logistics complex.

- The introduction of the so called Internet things will help track and manage transport and cargo flows better.

- The introduction of driverless transport is currently under great question. On the one hand, the level of technology development allows organizing unmanned cargo delivery and many companies are working on the development of unmanned cargo transport, on the other hand, today there are many restrictions in the legal field [22-24].

\section{Discussion}

According to the authors of this work, they managed to identify the issue of the impact of digitalization on the functional responsibilities of personnel involved in the subsystems of the logistics system. But the result is quite generalized.

For more detailed study of this issue, it is necessary:

- to make observations and calculations of all operations performed by the personnel of organizations involved in logistics;

- to calculate the time spent on carrying out operations by automated systems and personnel currently carrying out these operations;

- to assess the feasibility of replacing a part of the personnel with automated systems or their use when increasing the volume of work performed;

- to give recommendations on the implementation of automated systems, depending on the type of activity of the organization;

- to predict technology availability. 


\section{Conclusions}

In the article, the authors have collected and presented the entire list of job functions of employees involved in the logistics complex. We managed to identify and describe 22 positions. Based on the analysis of job functions, 4 groups were identified: Specialist in the field of digital logistics (Logistics analyst), Employee / Specialist of the Contract Service, Foreign trade Manager, Transport logistics. The impact of digitalization on these groups is described.

In the near future the profession of a logistician will be significantly transformed, but, in view of the significant financial costs in the implementation of information technologies and production automation, in the nearest future, especially for Russia, no significant changes are expected.

The introduction of information technologies in the field of foreign trade managers' activity began in the 90s, and continues successfully today. However, in the coming years, we can talk only about automating routine operations (such as filling out and submitting documents). The use of blockchain platforms or full automation of technological processes in the processing of international cargo in the nearest future in Russia is not possible.

At present digitalization is a highly influencing factor in transport logistics. Internet of things technology is widely used in transport logistics, but the possibilities are far from exhausted. Unmanned vehicles may also be widely used in the future. The survey showed that only $28 \%$ of organizations in the transport and logistics complex rate their level of digital development as "advanced".

\section{References}

1. V. Sergeyev, Journal Logistics and supply chain management, 3-30 (2018)

2. Antal Russia, Labor market research and salary survey (2016) https://antalrussia.ru

3. Coyle Bardi Langley, The Management of business logistics (West Publishing Co, St. Paul, MN, 1992)

4. V. Sergeyev, Transport and Telecommunication 17(2), 100-110 (2018)

5. A. Klimov, V. Kupriyanovsky, I. Sokolov, E. Zarechin, J. Kupriyanovsky, Journal International journal of open information technologies, 98-127 (2019)

6. V. Kupriyanovsky, International journal of open information technologies 5.3, 117-132 (2017)

7. V. Kupriyanovsky, International journal of open information technologies 5.3, 79-99 (2017)

8. Transport 2040: Automation, technology, employment - The Future of Work (International Transport Workers' Federation (ITF), London, UK, 2019)

9. G. Hefler, E. Steinheimer, J. Wulz, Literature review on initiatives to improve early career conditions across EU member states (WP7), https://h2020enliven.files.wordpress.com

10. A. Anisiforov, A. Dubgorn, A. Lepekhin, E3S Web of Conferences 110, 02051 (2019)

11. STRIA Roadmap on Connected and Automated Transport Road, Rail and Waterborne (2019) https://trimis.ec.europa.eu/sites/default/files/roadmaps/stria_roadmap_2019connected_and_automated_transport.pdf

12. Skills for Smart Industrial Specialization and Digital Transformation. Interim Report (2018) https://op.europa.eu/en/publication-detail/-/publication/21a549e7-05c8-11ea$8 \mathrm{c} 1 \mathrm{f}-01 \mathrm{aa} 75 \mathrm{ed} 71 \mathrm{a} 1 /$ language-en 
13. R. Okorokov, A. Timofeeva, T. Kharlamova, IOP Conference Series: Materials Science and Engineering (2019) https://doi.org/10.1088/1757-899X/497/1/012015

14. The High-Level Expert Group on the Impact of the Digital Transformation on EU Labour Markets (2019) https://ec.europa.eu/digital-single-market/en/news/final-reporthigh-level-expert-group-impact-digital-transformation-eu-labour-markets/

15. World experience of using RFID in logistics, http://www.idexpert.ru/reviews

16. D. Egorov, A. Levina, S. Kalyazina, P. Schuur, B. Gerrits, Lecture Notes in Networks and Systems 157, 201-209 (2021)

17. Benefits from the introduction of electronic data exchange, https://topby.by/help/edi_about

18. Sales management definition, process, strategies and resources, https://www.pipedrive.com/en/blog/sales-management

19. International transportation: yesterday, today, tomorrow, https:/www.kp.ru/guide/mezhdunarodnye-gruzoperevozki.html

20. Container turnover in the Russian Railways system increased to 2 million TEU in 5 months, http://infranews.ru/logistika/containeri/54264-oborot-kontejnerov-v-sistemerzhd-vyros-do-2-mln-teu-za-5-mesyacev

21. T.V. Alesinskaya, D.V. Arutyunova, V.G. Orlova, I.V. Ilin, S.V. Shirokova, Academy of Strategic Management Journal 16(1), 10-20 (2017)

22. 10 ways a document management system reduces operational costs, https://www.openkm.com/blog/10-ways-a-document-management-system-reducesoperational-costs.html

23. V. Demin, State and development trends of transport logistics in Russia. An overview of key performance indicators in road transport, http://www.eclogistics.ru/articles/sostoyanie-i-tendencii-razvitiya-transportnoj-logistiki-v-rossii

24. S. Fedotova, Digitalization of transportation and logistics services. Journal Economy and business: theory and practice (2019) 